\title{
Dynamic behaviour of HPFRCC: The influence of fibres dispersion
}

\author{
Alessio Caverzan $^{1,2, a}$, Marco di Prisco ${ }^{1}$, and Ezio Cadoni ${ }^{3}$ \\ ${ }^{1}$ Department of Civil and Environmental Engineering, Politecnico di Milano, 20133 Milano, Italy \\ ${ }^{2}$ Present Address: European Commission, Joint Research Centre (JRC), Institute for the Protection and Security of \\ the Citizen (IPSC), European Laboratory for Structural Assessment (ELSA), 21027 Ispra, Italy \\ ${ }^{3}$ DynaMat Laboratory, University of Applied Sciences of Southern Switzerland, 6952 Canobbio, Switzerland
}

\begin{abstract}
The promise of fibre-reinforced cementitious composites for dynamic loading application stems from their observed good response under static loading mainly due to fibre contribution. An experimental research aimed at contributing to the understanding of the behaviour of advanced fibre-reinforced cementitious composites subjected to low and high strain rates was carried out underlining the influence of fibres. The material behaviour was investigated at three strain rates $(0.1,1$, and $\left.150 \mathrm{~s}^{-1}\right)$ and the tests results were compared with their static behaviour. Tests at intermediate strain rates $\left(0.1-1 \mathrm{~s}^{-1}\right)$ were carried out by means of a hydro-pneumatic machine (HPM), while high strain rates $\left(150 \mathrm{~s}^{-1}\right)$ were investigated by exploiting a modified Hopkinson bar (MHB). Particular attention has been placed on the influence of fibre and fibre dispersion on the dynamic behaviour of the materials: matrix, HPFRCC with random fibre distribution and aligned fibres were compared. The comparison between static and dynamic tests highlighted several relevant aspects regarding the influence of fibres on the peak strength and post-peak behaviour at high strain rates.
\end{abstract}

\section{Introduction}

The mechanical behaviour of fibre-reinforced cementitious composites when subjected to impact or blast still has many aspects requiring further studies [1], with specific reference to large and socially-sensitive structures, as sheltering structures, high-rise buildings, bridges, offshore platforms, pipelines, gasification reactors, secondary containment shells for nuclear power plants, and tunnels. In the last decade a particular class of cementitious materials defined High Performance Fibre Reinforced Cementitious Composites (HPFRCC) has been taken into consideration as a promising solution by many researchers due to the materials characteristics [2]. HPFRCCs are characterized by high ductility and tension hardening behaviour in statics. The high energy absorbed during the fracture process is associated to multiple cracking and pull-out phenomena. The good response highlighted in the static field by many researchers suggests using these materials also for dynamic loading applications. However, very few investigations have been carried out in order to guarantee the improvement of the dynamic response. Current understanding of the impact resistance of cementitious composites, and especially of highstrength concrete, is very limited [3,4]. Moreover, the results available in the literature are also often contradictory. For example, while some researchers [5-7] reported a progressively reduced sensitivity to strain rate with the growing of the static compressive strength of concrete, other studies contrast this opinion [8].

Fibers enhance the ductility of brittle materials like concrete, and this improvement is strictly related to the

\footnotetext{
${ }^{a}$ Corresponding author: alessio.caverzan@jrc.ec. europa.eu
}

process by which load is transferred from matrix to fibers and the bridging effect of fibers across the cracks. Hence fiber pull-out is the principal mechanism contributing to the high toughness of the material, thus preventing fiber failure mechanism. Since, the behavior of the fiber, the cement matrix and the bond interface (or the pull-out mechanism) are likely dependent on the strain rate, it is expected that the strain rate sensitivity moves to the composite level [9].

However, the researches quoted were not focused on the influence of fiber reinforcement in the strength increase at high strain rates, if any. Caverzan et al. [10] have pointed out that fibers increase the peak strength in static, favoring the stable crack propagation, but when the strain rate is increased, fiber influence on the stable crack propagation phenomena reduces: at high strain rates the peak strength ratio between HPFRCC and HPCC decreases. Starting from this observation, in this work the fiber role is investigated at different strain rates comparing the results obtained for a plain and fiber reinforced HPCC. In particular, two different kinds of HPFRCCs have been considered in order to underline the influence of fibres distribution in the matrix. The two reinforced materials are characterized by different casting procedures that have led to different fibre dispersion and orientation, HPFRCCA was characterized by a homogeneous dispersion of fibres which were all aligned to the load direction. On the contrary, HPFRCC-R had a random fibre distribution and no preference fibre direction can be highlighted.

\section{Material and casting procedure}

This research studies a high performance cementitious composite optimised with steel fibres. The mix design of 
Table 1. Mix design.

\begin{tabular}{lc}
\hline Constituent & $\begin{array}{c}\text { dosage } \\
{\left[\mathrm{kg} / \mathrm{m}^{3}\right]}\end{array}$ \\
\hline Cement type I 52.5 & 600 \\
Slag & 500 \\
Water & 200 \\
Sand 0-2 mm & 983 \\
Fibres $\left(l_{f}=13 \mathrm{~mm} ; d_{f}=0.16 \mathrm{~mm}\right)$ & 100 \\
Super plasticiser & $331 / \mathrm{m}^{3}$ \\
\hline
\end{tabular}

the HPFRCC material is specified in Table 1. The steel fibres were high carbon straight fibres, $13 \mathrm{~mm}$ long with a $0.16 \mathrm{~mm}$ diameter (aspect ratio $l_{f} / d_{f}$ equal to 80 ); their proportion in the mix was equal to $100 \mathrm{~kg} / \mathrm{m}^{3}$.

The sand used in the material was sieved up to $2 \mathrm{~mm}$ and it can be classified as mixed quartz sand. A $1.6 \mathrm{~m} \times 0.60 \mathrm{~m}$ in plane slab, $30 \mathrm{~mm}$ thick, was manufactured. The slab was cast by applying a unidirectional flow as shown. In order to guarantee a certain fibre orientation, the properties of the self compacting material were used, taking advantage of the flow direction. Three prismatic beam samples, $40 \mathrm{~mm}$ wide and $600 \mathrm{~mm}$ long, were sawed from the slab and tested in bending to perform a proper mechanical characterisation of the material according to Italian Guidelines [11]. The high fibre content and the favourable orientation imposed by the casting flow control allow us to guarantee a small dispersion of the response before and after single-crack localisation and a hardening behaviour in uniaxial tension. From the bent specimens, several small cylinders $20 \mathrm{~mm}$ long, labeled HPFRCC-A, were cored in the direction of tensile stresses. Their diameter was nominally equal to $20 \mathrm{~mm}$. Each cylinder cored from each prismatic specimen was notched (notch depth $=1.5 \mathrm{~mm}$ ), to be tested in uniaxial tension at different loading rates. HPFRCC-R samples were cored from different prismatic specimens used to perform the mechanical characterization of the material according to National Recommendations [12], three prismatic specimens were cast. Specimens were $150 \mathrm{~mm} \times 150 \mathrm{~mm}$ cross-section and $600 \mathrm{~mm}$ long. Due to the high viscosity of the material at fresh state, it was not possible to cast them using a trowel with a minimum opening equal to $200 \mathrm{~mm}$, as suggested by UNI 11039 [12], but they were cast in steel formworks by applying a flow at the right angle with the longer formwork side. After 28 days, the beams were notched in the middle of the face close to the casting surface by means of a diamond saw. The notched specimens were tested in bending. After performing the bending tests, the specimens were divided into two halfs and more cores were taken from each half. The cores object of the present work have a dimeter equal to $20 \mathrm{~mm}$, then these cores where cut and notched in order to obtain samples identical to the samples HPFRCCA previously described. The matrix of the HPFRCCs materials previously described has been used as a reference plain high performance composite (HPCC). The casting procedure adopted, and described above, for the HPFRCCA sample has been used to produce the nothced cylindrical samples of HPCC. The cylindrical samples were tested in static and dynamic range.

\section{Static tests}

Uniaxial tensile tests on notched cylindrical specimens have been performed with an electro-mechanical testing machine INSTRON 5867 at the laboratory of the Politecnico di Milano - Polo Regionale di Lecco. The press has a maximum loading capacity of $30 \mathrm{kN}$. The samples have been glued to the press platens by means of an epoxy resin. Two aluminum cylinders, connected to the press by a knuckled joint, have been used as press platens. In both cylinders, a $5 \mathrm{~mm}$ deep cylindrical cavity with a $22 \mathrm{~mm}$ diameter was made in order to increase the glued sample surface. Stroke was considered as feedback parameter during the tests. The displacement rate imposed during the tests was equal to $5 \times 10^{-5} \mathrm{~mm} / \mathrm{s}$ up to $1.5 \mathrm{~mm}$ and then it was progressively increased to $10^{-3} \mathrm{~mm} / \mathrm{s}$. Test results are shown in Fig. 1 in terms of nominal stress $\left(\sigma_{N}\right)$ versus crack opening displacement (COD) for the HPFRCC-A and HPFRCC-R materials, while in Table 2 are reported the peak strength values, the effective cross section area and the number of fibers counted in the failed sections for the HPFRCC aterials and the HPCC as well. Due to a defect identified in the sample 3 only two specimens were tested for the HPCC. Considering the cavity depth of the platens ( $5 \mathrm{~mm}$ for each side, where samples are glued) as a rigid zone, a clear span equal to $10 \mathrm{~mm}$ can be used to compute the strain, starting from the COD values.

On the basis of this assumption, it is interesting to observe that aligned steel fibers are able to favor stable propagation up to a strain of about $2 \%$ in the HPFRCCA material (Fig. 1(a)). The pre-peak behavior is well described by a parabola rectangular model. This would mean that, even if a notch depth ratio equal to 0.15 was used, the material is hardening and it distributes over the whole clear length the cracking process. Of course, the geometrical defect introduced by the notch and the only stroke measure prevents a correct evaluation of the effective ductility measured in terms of strain of the peak plateau. New tests without any notch are in progress. A peak strength increase of about $40 \%$ can be pointed out comparing the results obtained for the HPCC. The fibers favor a more stable crack propagation leading to the increase of peak strength in the static field. Moreover, it is interesting to highlight the low peak strength measured and the softening post-peak behaviour in the HPFRCC$\mathrm{R}$ which is characterised by a random fibre distribution. Figure 1(b) shows a drop to a stress plateau of about 1.5 MPa after the peak. In these specimens, fibres were not able to promote the stable crack propagation mainly due to their random distribution. The number of fibres and their orientation was completely different from that obtained by applying an unidirectional flow during the cast procedure. Also the decay in the peak strength could be partly related to the random fibre distribution, now fibres can be assimilated to an internal defect, which could cause the observed decrease in the peak strength. These considerations underline that the cast procedures play a relevant role in this kind of materials. Performing the same tests on specimens with the same geometry a decrease of about $50 \%$ in the peak strength is observed.

On the basis of this assumption, it is interesting to observe that aligned steel fibers are able to favor stable 


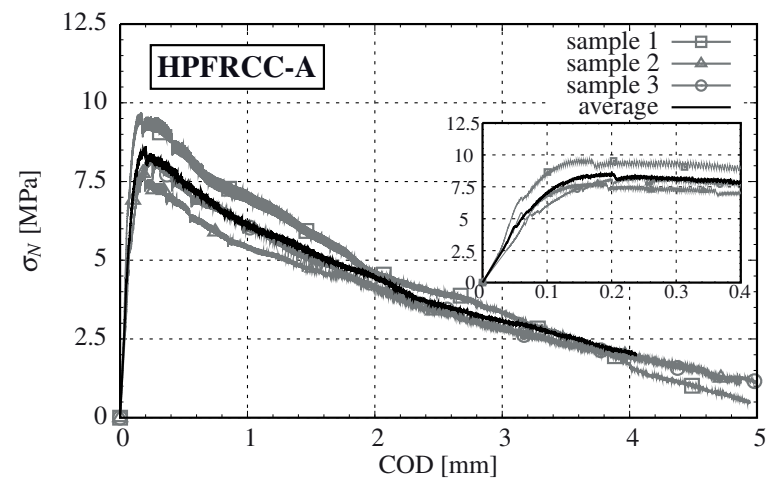

(a)

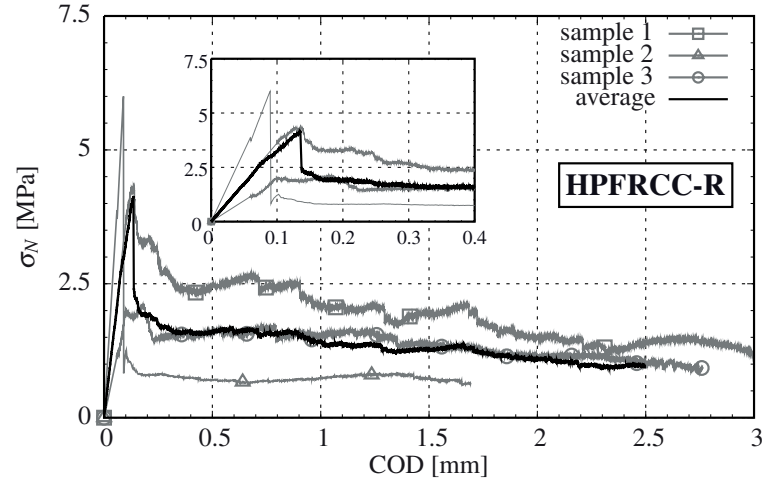

(b)

Figure 1. Test results: material with alligned fibres (HPFRCC-A) (a); material with random fibre distribution (HPFRCC-R) (b).

Table 2. Peak strengths and number of fibres.

\begin{tabular}{ccccc}
\hline $\begin{array}{c}\text { Material } \\
\text { type }\end{array}$ & $\begin{array}{c}\text { sample } \\
\mathrm{n}^{\circ}\end{array}$ & $\begin{array}{c}\text { fibre } \\
\mathrm{n}^{\circ}\end{array}$ & $\begin{array}{c}\sigma_{\text {Peak }} \\
{[\mathrm{MPa}]}\end{array}$ & $\begin{array}{c}\sigma_{\text {Peak }, a v} \\
{[\mathrm{MPa}]} \\
(\mathrm{std})\end{array}$ \\
\hline HPFRC-A & 1 & 75 & 9.71 & \\
HPFRC-A & 2 & 73 & 7.83 & 8.62 \\
HPFRC-A & 3 & 77 & 8.33 & $(0.97)$ \\
HPFRC-R & 1 & 20 & 4.32 & \\
HPFRC-R & 2 & 31 & 6.03 & 4.15 \\
HPFRC-R & 3 & 27 & 2.10 & $(1.97)$ \\
HPC & 1 & - & 6.81 & \\
HPC & 2 & - & 5.50 & 6.15 \\
HPC & 3 & - & - & $(-)$ \\
\hline
\end{tabular}

propagation up to a strain of about $2 \%$ in the HPFRCCA material (Fig. 1(a)). The pre-peak behavior is well described by a parabola rectangular model. This would mean that, even if a notch depth ratio equal to 0.15 was used, the material is hardening and it distributes over the whole clear length the cracking process. Of course, the geometrical defect introduced by the notch and the only stroke measure prevents a correct evaluation of the effective ductility measured in terms of strain of the peak plateau. New tests without any notch are in progress. A peak strength increase of about $40 \%$ can be pointed out comparing the results obtained for the HPCC. The fibers favor a more stable crack propagation leading to the increase of peak strength in the static field. It is interesting to highlight the low peak strength measured and the softening post-peak behaviour. Figure 1(b) shows a drop to a stress plateau of about 1.5 MPa after the peak. In these specimens, fibres were not able to promote the stable crack propagation mainly due to their random distribution. The number of fibres and their orientation was completely different from that obtained by applying an unidirectional flow during the cast procedure. Also the decay in the peak strength could be partly related to the random fibre distribution, now fibres can be assimilated to an internal defect, which could cause the observed decrease in the peak strength. These considerations underline that the cast procedures play a relevant role in this kind of materials. Performing the same tests on specimens with the same geometry a decrease of about $50 \%$ in the peak strength is observed.

\section{Dynamic tests}

In order to identify the influence of fibers and fibres dispertion on the material response under dynamic conditions an experimental program has been carried out. Two different mechanical testing machines have been used to investigate the dynamic field: a hydro-pneumatic machine (HPM) has been employed to investigate the strain rates equal to 0.1 and $1 \mathrm{~s}^{-1}$ while a modified Hopkinson bar (MHB) [13] has been exploited to carry out high strain rate tests $\left(150 \mathrm{~s}^{-1}\right)$. The HPM functioning is widely described in [14], here only a briefly description of the device is reported. At the beginning of the test, a sealed piston divides the cylindrical tank into two chambers, one being filled with gas at high pressure (viz. 150 bars), and the other with water. An equal pressure is initially established in the water and gas chambers so that the forces acting on the two faces of the piston are in equilibrium. The test starts when the second chamber discharges the water through a calibrated orifice that is activated by a fast electro-valve. The piston starts then to move, expelling the water. The specimen is connected on one side to the piston shaft and, on the other side, to the end of an elastic bar which is rigidly fixed to a supporting structure. The elastic bar is instrumented with a strain-gauge that provides, through the elastic properties of the bar, the force acting on the specimen during the test. Two targets are attached at both ends of the specimen and their movement is measured by two contact-less displacement transducers. The MHB consists of two circular aluminum bars, called input and output bars (with a diameter of $20 \mathrm{~mm}$ and having length of 3 and $6 \mathrm{~m}$, respectively) between which the specimen is glued using a bi-component epoxy resin. The input bar is connected to a high strength steel pretension bar (having $6 \mathrm{~m}$ length and $12 \mathrm{~mm}$ diameter), used as pulse generator. A test with the MHB starts pulling the high strength steel bar by means of a hydraulic actuator (of maximum loading capacity of $600 \mathrm{kN}$ ); the pretension stored in this bar is assured by the blocking device. In the second operation the fragile bolt in the blocking device is ruptured, giving rise to a tensile mechanical pulse of duration $2.4 \mathrm{~ms}$ and with a linear loading rate during the rise time. The pulse 


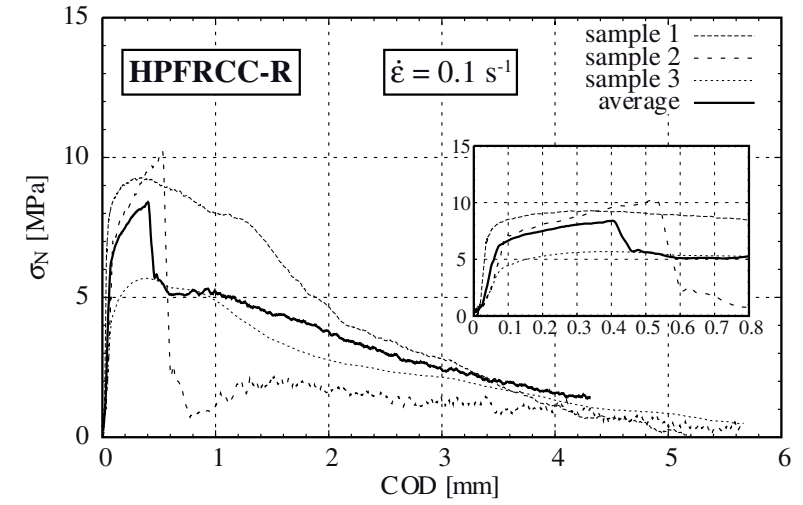

Figure 2. Stress vs. strain curves for the dynamic tests with a strain rate $\dot{\varepsilon}$ equal to $0.1 \mathrm{~s}^{-1}$.

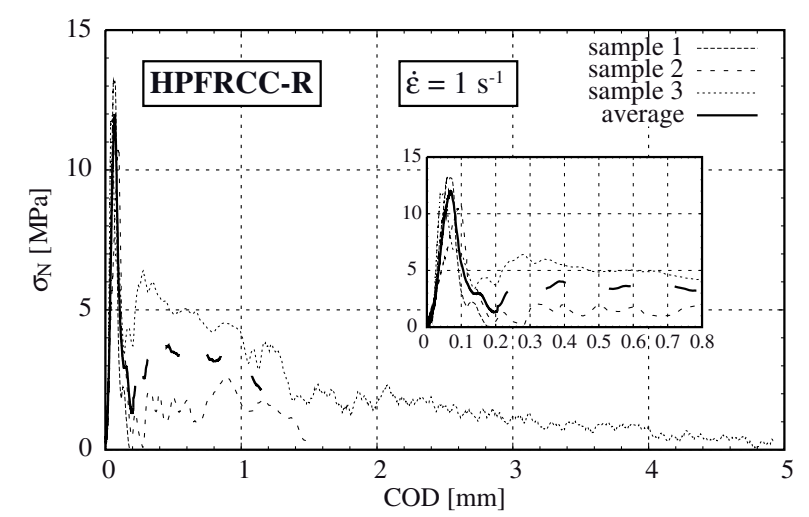

Figure 3. Stress vs. strain curves for the dynamic tests with a strain rate $\dot{\varepsilon}$ equal to $1 \mathrm{~s}^{-1}$.

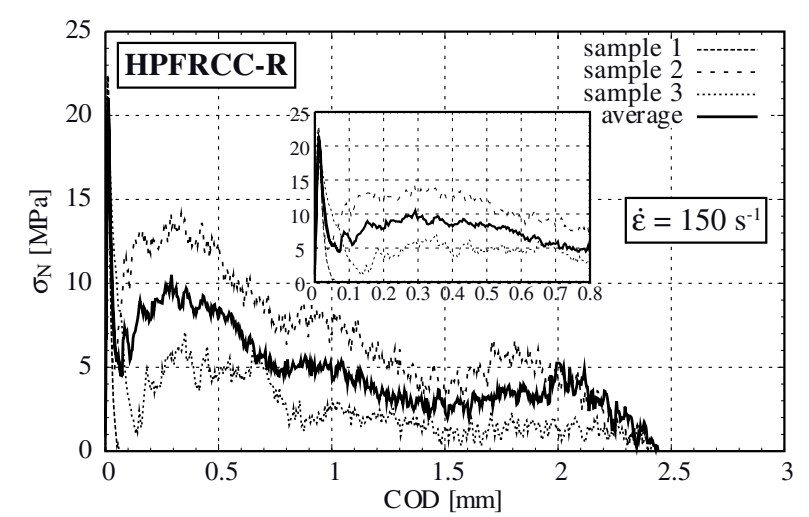

Figure 4. Stress vs. strain curves for the dynamic tests with a strain rate $\dot{\varepsilon}$ equal to $150 \mathrm{~s}^{-1}$.

then propagates along the input and output bars, leading the specimen to failure. In Figs. 2, 3 and 4 the stress versus COD curves of the HPFRCC-R specimens tested at $0.1,1$ and $150 \mathrm{~s}^{-1}$ respectively are reported. In Fig. 5 only the average curves for the HPFRCC specimens are presented [3] while the complete trends for the dynamic behaviour of HPCC are reported in [10].

The peak strength values and the number of fibers counted in the failed cross sections are listed in Table 3. Analyzing the test results, some interesting considerations can be highlighted. An increasing of peak strength can

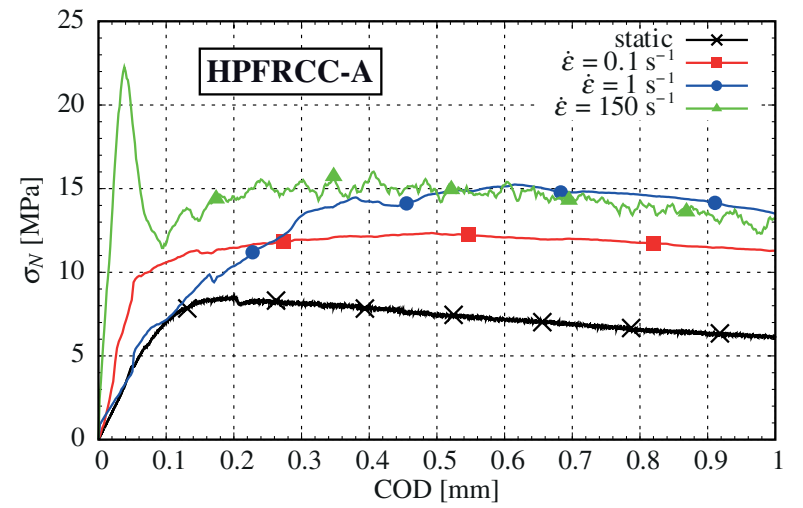

Figure 5. Stress vs. strain curves for the dynamic tests with a strain rate $\dot{\varepsilon}$ equal to $150 \mathrm{~s}^{-1}$.

Table 3. Peak strengths and number of fibres.

\begin{tabular}{|c|c|c|c|c|}
\hline $\begin{array}{c}\text { Strain rate } \\
{\left[\mathrm{s}^{-1}\right]}\end{array}$ & $\begin{array}{c}\text { Material } \\
\text { type }\end{array}$ & $\begin{array}{c}\text { fibre } \\
\mathrm{n}^{\circ}\end{array}$ & $\begin{array}{c}\sigma_{P e a k} \\
{[\mathrm{MPa}]}\end{array}$ & $\begin{array}{c}\sigma_{P e a k, a v} \\
{[\mathrm{MPa}](\mathrm{std})}\end{array}$ \\
\hline \multirow{3}{*}{0.1} & HPFRC-A & $\begin{array}{l}75 \\
73 \\
77\end{array}$ & $\begin{array}{l}9.71 \\
7.83 \\
8.33\end{array}$ & $8.62(0.97)$ \\
\hline & HPFRC-R & $\begin{array}{l}50 \\
22 \\
33\end{array}$ & $\begin{array}{c}9.28 \\
10.25 \\
5.68\end{array}$ & $8.40(2.40)$ \\
\hline & HPC & $\begin{array}{l}- \\
- \\
-\end{array}$ & $\begin{array}{c}10.54 \\
7.87 \\
8.95\end{array}$ & $9.12(1.34)$ \\
\hline \multirow{3}{*}{1} & HPFRC-A & $\begin{array}{l}76 \\
71 \\
73 \\
77\end{array}$ & $\begin{array}{l}14.29 \\
14.09 \\
17.67 \\
14.96\end{array}$ & $15.25(1.65)$ \\
\hline & HPFRC-R & $\begin{array}{l}26 \\
20 \\
27\end{array}$ & $\begin{array}{l}13.21 \\
10.84 \\
11.95\end{array}$ & $12.00(1.19)$ \\
\hline & HPC & $\begin{array}{l}- \\
- \\
-\end{array}$ & $\begin{array}{l}10.22 \\
11.33 \\
12.36\end{array}$ & $11.31(1.07)$ \\
\hline \multirow{3}{*}{150} & HPFRC-A & $\begin{array}{l}79 \\
90 \\
79 \\
81\end{array}$ & $\begin{array}{l}20.46 \\
22.28 \\
24.96 \\
21.74\end{array}$ & $22.36(1.89)$ \\
\hline & HPFRC-R & $\begin{array}{l}20 \\
61 \\
26\end{array}$ & $\begin{array}{l}22.40 \\
22.57 \\
18.16\end{array}$ & $21.04(2.50)$ \\
\hline & HPC & $\begin{array}{l}- \\
- \\
-\end{array}$ & $\begin{array}{l}15.89 \\
18.48 \\
16.77\end{array}$ & $17.05(1.32)$ \\
\hline
\end{tabular}

be observed with respect to the static one, nevertheless specimen HPFRCC-R showed a peak strength lower than that highlighted for HPFRCC-A samples as it can be seen in Table 3, where the peak strength values and the number of fibers counted in the failed cross sections are listed. Moreover a peak strength increase has been observed increasing the strain rate from 0.1 to $1 \mathrm{~s}^{-1}$ for the same material type. The comparison between dynamic response of specimens HPFRCC-A and HPFRCC-R showed to what 
Table 4. Dynamic Increase Factors of peak strengths.

\begin{tabular}{cccc}
\hline Strain rate & $\mathrm{DIF}_{H P F C C-A}$ & $\mathrm{DIF}_{H P F R C C-R}$ & $\mathrm{DIF}_{H P C}$ \\
\hline 0.1 & 1.43 & 2.03 & 1.48 \\
1 & 1.77 & 2.90 & 1.84 \\
150 & 2.59 & 5.08 & 2.77 \\
\hline
\end{tabular}

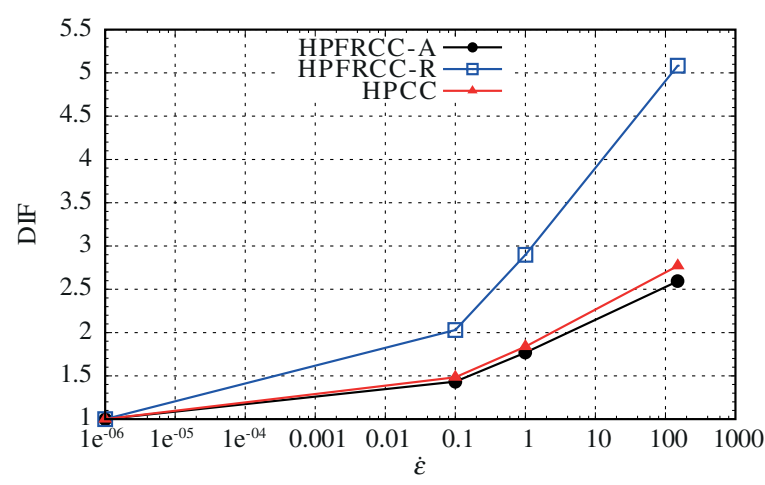

Figure 6. Dynamic increase factors (DIFs) versus strain rates.

extent the cast procedure, and the resulting random fibre distribution, can influence not only the static material behaviour but also the dynamic one. Considering high strain rate $\left(150 \mathrm{~s}^{-1}\right)$ carried out on specimens HPFRCCA (see Fig. 5) stresses drop down to a stress plateau after the peak strength. Because of fibre random distribution, in the HPFRCC-R samples the stress plateau has a value of about $10 \mathrm{MPa}$ (30\% less than the HPFRCC-A plateau) up to a crack opening displacement of about $4 \mathrm{~mm}$.

In order to evaluate the peak strength trend in the dynamic field the dynamic increase factor (DIF) can be considered. The dynamic increase factors are listed in Table 4 and they have been computed as the ratio between the dynamic strength of the material $\left(\sigma_{P e a k, d}\right)$ and the static strength of the material $\left(\sigma_{P e a k, s}\right)$. In Fig. 6 DIFs versus strain rate are plotted for the HPFRCCs and the HPCC as well. The DIF parameter can be used to quantify the rate sensitivity of these materials, HPFRCC-A and HPC have showed a comparable trend in the strain rate range investigated. However the HPCC material denoted a higher values of DIF for all the strain rates. Moreover, HPFRCC$\mathrm{R}$ exhibites high values of DIF comperate to what observed for the material characterised by aligned fibres (HPFRCCA). The main reason is associated with the low peak strength recorded in the static regime which have led to an increase of the DIF values.

To clarify contribution of fibre and their dispetion on the peak strength increase, the ratio between HPFRCCs and the HPCC peak strengths $\left(\sigma_{\text {Peak }}^{H P F C C} / \sigma_{\text {Peak }}^{H P C C}\right)$ for all the strain rates investigated are plotted in Fig. 7. Several interesting considerations can be highlighted. In the static field aligned fibers (HPFRCC-A) strongly influence the stable crack propagation leading to an increase of the peak strength of about $40 \%$. However, when random fibres dispersion and orientation (HPFRCC-R) are considered the stable crack propagation has not been favored, fibres acted as a defect in the matrix leading to a decay in the peak strength of about $30 \%$. When the strain rate increases a reduction of the fibers influence can be observed. Passing

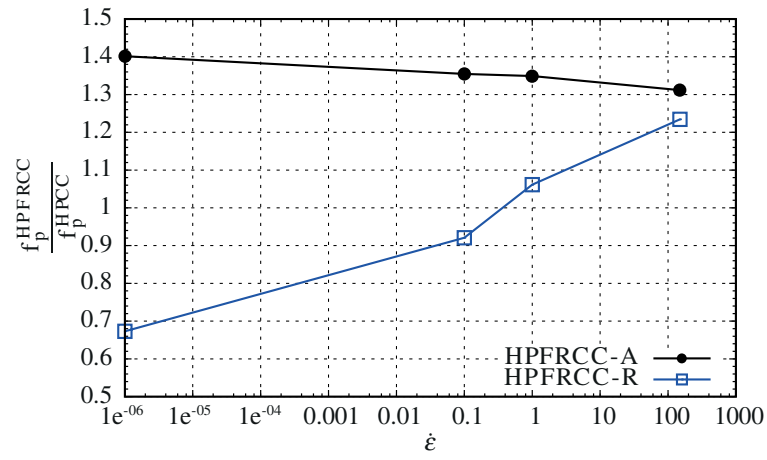

Figure 7. Peak strength ratio versus strain rate.

from 0.1 to $150 \mathrm{~s}^{-1}$ peak strength of HPFRCC-A material grows less (35-30\%) with respect to the static one. On the contrary, HPFRCC-R exhibits a sensible increase of the peak strength ratio when strain rates increases. Hence, in the dynamic regime the influence of fibres on the peak strength is reduced as the reduction of gap between HPFRCC-A and HPFRCC-R peak ratio suggests (Fig. 7). When high strain rate $\left(150 \mathrm{~s}^{-1}\right)$ is considered the peak ratio values are almost coincided. Fibres, specially inf randomly distributed and oriented, could be considered as defects in the matrix which become less important when strain rates are increased. A plausible physical explanation of this behaviour is that at higher strain-rates all particles of the material are accelerated under the action of the very fast growing loading pulse, resulting in a more uniform distribution of strain and strain energy. Consequently the influence of existing single defects and voids becomes less important, as the whole material volume works together to resist the applied load which is similar to the theory of multiactivation of the fracture process at impact regime [15].

\section{Conclusions}

The behaviour of HPFRCC and HPCC materials when subjected to different strain rates was investigated. From the experimental results presented in this research work some important conclusions can be drawn:

- the comparison between static and variable strain rate tests, carried out by means of three different mechanical devices, exhibits high values of the dynamic increase factor for the HPCC and the HPFRCCs characterised by aligned and random distributed fibres;

- the rate sensitivity of HPCC seems to be higher than what observed for HPFRCC-A with aligned fibres. In fact, HPCC material has denoted a weakly higher values of DIF for all the strain rates investigated. Moreover, HPFRCC-R showed the highest trend of DIF characterised by increments between the $37 \%$ and the $103 \%$;

- aligned fibers increase the peak strength in static of about $40 \%$, favoring the stable crack propagation. When the strain rate is increased, fiber influence on the stable crack propagation phenomena reduces: at high strain rates the peak strength ratio between HPFRCCA and HPCC decreases to $30 \%$; 
- random fibres dispersion and orientation (HPFRCC-R) have not favored the stable crack propagation, fibres acted as defects in the matrix leading to a decay in the peak strength of about $30 \%$ with respect to what exhibited by HPCC;

- in the dynamic regime the influence of fibres on the peak strength is reduced as the reduction of gap between HPFRCC-A and HPFRCC-R peak ratio has suggested; when high strain rate $\left(150 \mathrm{~s}^{-1}\right)$ is considered the peak ratio values are almost coincided.

\section{References}

[1] V. Bindiganavile, N. Banthia, Tech. rep., ACI 544 Technical Commission (2007)

[2] D.j. Kim, S. El-Tawil, A. Naaman, Materials and Structures 42, 399 (2009)

[3] A. Caverzan, E. Cadoni, M. di Prisco, International Journal of Impact Engineering 45, 28 (2012)

[4] A. Caverzan, E. Cadoni, M. di Prisco, Mechanics of Materials 59, 87 (2013)

[5] N. Banthia, S. Mindess, A. Bentur, M. Pigeon, Experimental Mechanics 29, 63 (1989)

[6] A. Bentur, S. Mindess, N. Banthia, Society for Experimental Mechanics pp. 449-458 (1987)
[7] C. Ross, Review of Strain Rate Effects in Materials, in Structures under Extreme Loading Conditions (1997), ASME Pressure Vessels and Piping Conference, pp. 255-262

[8] P.H. Bischoff, S.H. Perry, J. Engrg. Mech. 121, 685 (1995)

[9] D. Kim, S. El-Tawil, A. Naaman, ACI Materials Journal 105, 576 (2008)

[10] A. Caverzan, E. Cadoni, M. di Prisco, in RILEM State of the Art Reports, edited by G. ParraMontesinos, H. Reinhardt, A. Naaman (Springer Netherlands, 2012), Vol. 2, pp. 339-346-, http:// dx . doi .org/10.1007/978-94-007-2436-5_41

[11] A. Caverzan, M. Colombo, M. di Prisco, B. Rivolta, Materials and Structures On line first, 1 (2015)

[12] UNI 11039, Concrete Reinforced with Steel Fibres. Part II: Test Method for the Determination of First Cracking Strength and Ductility Indexes (2003)

[13] E. Cadoni, C. Albertini, G. Solomos, J. Phys. IV France 134, 647 (2006)

[14] D. Asprone, E. Cadoni, A. Prota, G. Manfredi, International Journal of Rock Mechanics and Mining Sciences 46, 514 (2009)

[15] E. Cadoni, G. Solomos, C. Albertini, Magazine of Concrete Research 61, 221 (2009) 